\title{
Theoretical and methodological foundations of profiling as an interdisciplinary field of psychological knowledge
}

\author{
Bella Psareva $^{1, *}$, and Alexandra Gamayunova ${ }^{1}$ \\ ${ }^{1}$ Altai State University, 656049, 61a Lenina ave., Barnaul, Russia
}

\begin{abstract}
The article discusses one of the new applied areas in psychology, which is the non-instrumental diagnosis of lie, i.e.profiling. Currently, one of the new applied areas in psychology is profiling. Modern profiling includes knowledge, abilities, and skills (hereinafter, KAS), developed on the basis of the achievements of contemporary Psychological Science, a clear affiliation to a specific subject. The basis of integrative psychotechnology is a complex of knowledge in Psychological Sciences, where the object of general knowledge is the personality, his/her features, behavior, and general psychological laws of organizing purposeful activity. The authors come to the conclusion that profiling is an area of theoretical, methodological, integrated, scientifically grounded knowledge in related disciplines of Psychological Science.
\end{abstract}

Currently, in Psychological Science, many new applied areas are developing, one of which is profiling. The technique of "profiling," from a practical point of view of E. I. Foigel and A. A. Kozulova, is a technique from applied, zero-test, full-time psychological methods and techniques of visual psychodiagnostics of personal psychological characteristics of a particular subject (character, behavior, emotional state, intelligence, motives, values, habits, preferences, interests, inclinations, complexes, weaknesses, advantages, attitudes, beliefs, goals, strategies, psychotype, social status, and the ability to lie), using a special methodology to: a) evaluate, explain the causes of behavior, behavioral reactions; b) formulate hypotheses (probable assumptions), forecasting, and management scenarios for the development of situations, possible actions, as well as patterns of behavior and human communication in the future and in certain situations; c) verify (non-verbal diagnosis of lies, NVDL) [1].

Methodology and profiling tools [2, 3], including for verifying a lie by analyzing its verbal and non-verbal manifestations, within the psychology of lies, are some general scientific and special methods of legal psychology (according to research purposes).

The goal of operative psychodiagnostics is to study the external characteristics and appearance of a person to penetrate into the inner psychological content of the individual and use the individual capabilities of each person to form a profile (who that person is, how he/she thinks, what he/she is capable of, what he/she is inclined to). This method is wider

*Corresponding author: sofex_co@mail.ru 
than practical characterology, because not a character is considered, but personality is (i.e. individual characteristics). The mechanism for obtaining information is audiovisual, contactless, and non-instrumental. The instrumental mechanism is the evaluation using modern, technical-information tools and technologies of psychodiagnostics.

It forms the structure of simultaneous actions of a profiler:

a) A conversation that can be in the following forms: interview, psychological analysis of materials, a special survey scenario being developed, or selection of specific simple stimulus questions for psychological influence and disadaptation of the interlocutor's personality during tough negotiations (with criminal, terrorist, partner, client, or employeea). An instrumental and non-instrumental methods of studying and stimulating, analysis of truth criteria also could be used. Example: a special system of communicative interaction between the profiler and the suspects (passengers, visitors, masses of people, as well as participants in the criminal and civil process).

b) An observation, search, detection (remembering), fixation, memorization of a complex of dynamic behavioral private visually suspicious verbal and nonverbal external manifestations of non-standard reactions (and stimuli associated with them) by surrounding people through different channels in normal and immediately after the matter of interest, on certain tools and skills (for working with each channel their methods and tools). Signals of emotional and mental stress are:

- verbal-psycholinguistic, paralinguistic signs, speech content (answers to verification questions), voice quality (meaning of words, phrases, sentences, tone, voice, height, speech speed, stammering, stumbling, etc.);

- non-verbal, such as imperceptible movements, gestures, details (scratching, light lips touching, etc.), postures, order of actions, interpersonal distance, facial expressions, microexpressions, authentic emotions (inform regardless of the owner's desire - excitement, possible actions ("running", "fighting", "hiding") or lying);

- psychophysiological, psychoemotional reactions of the autonomic nervous system, appearance (clothing, physique), interaction with others in the process of communication (blood pressure, heart rate, palms sweating, etc.);

c) An analysis, comparison (comparison and contrast, inconsistency, a confident and reliable difference between the basic/usual behavior from the deviant/deceitful, and identifying significant and insignificant topics for the respondent), assessment, decision on the whole complex not random, recurring signs from all channels (from three main and three additional ones, only additional ones - not involvement, but stress, anxiety, probability of error, more signals - more accurately the conclusion about involvement, lies), diagnostics internal state, interpretation, decoding of information and external manifestations, the establishment of cause-effect relationships

The stress signal has several causes: the establishment of control and dominance over the interlocutor, for showing plausibility and honesty, shyness, the unpleasantness of the topic/question as a provoker of negative memories of a traumatic event (whether there is a connection with the event under investigation), indulgence, contempt, cultural and ethical origin, the level of extraversion, the degree of anxiety and suspiciousness, fatigue, recent stress, physiology (hot, cold, itchy nose, etc.), fear of the situation (for the first time during interrogation by the investigator, fear of distrust), the presence of others, or lying about the sacrament. Lies-signals are the stress. Stress reactions are not always a lie. We need evidence not for the fact of stress, but for its causes [4].

d) compiling a psycho-profile of the subject:

- basic profiling is the classification by psychotype (some features can be the stress signals of lies); 
- advanced profiling is the subsequent refinement and addition of individual psychological features inherent only to this person, such as behavior, reactions, a slight cough.

Individual psychological features are formed in the process of life, upbringing, socialization, adaptation under the influence of the social environment and genetics. They become transformed into the customary "personal list" of signals to overcome stress (voice, speech, gestures, running eyes, etc.) and can vary in the context of the situation, environment (close, personal, social, and public), and circumstances. The same signal in one situation demonstrates everything, but with different frequency, severity, etc. One behavior is the norm for one, but it is a lie signal for the other. There are many signals, but there is no typical behavior, patterns, and a certain concrete single.

Ignorance of the baseline, ignoring the individual characteristics of Brokaw hazard are the risk of false accusation (Othello's error), "losing" the real criminal. P. Ekmann introduced the concept in 1986 on the basis of the arguments of the famous American journalist Tom Brokaw on how to determine when the interlocutor is lying; "Many manifestations that often indicates a lie, for some people is part of their usual behavior" [5].

Thus, the toolkit is universal: a) conversation is a method of obtaining information that everyone uses (all are potentially able to speak, communicate, and this is generally the main way of collecting information for a lawyer); b) observation is the search and fixation of external manifestations with the help of sense organs (potentially everyone has it). Carrying out this algorithm requires general professional competence to observe (perception), to notice (attention), to distinguish (memory), and to analyze the cause (thinking).

It is necessary to raise the issue of the position of innovative technology in the system of scientific psychological branch knowledge. The modern paradigm of profiling with its theoretical and methodological foundations has come a long way of becoming and developing on the basis of applied researches of criminal investigators, forensic doctors, psychiatrists, criminal psychologists, and criminologists in the field of profiling a criminal's personality. That is why, they claim for its monopoly in today's Russia. Modern profiling includes KAS, developed on the basis of the achievements of contemporary Psychological Sciences, with a clear affiliation to a specific subject. The basis of integrative psychotechnics is a complex of knowledge of Psychological Sciences, where the object of general knowledge is the personality, his/her features, behavior, and general psychological laws of organization of purposeful activity. In particular, we can distinguish the following schools:

a) Schools of General Psychology (regularities and psychological implicit theories of personality: the goal is a general understanding of the individual, not verification of information):

- Behaviorism, "stimulus-reaction-behavior": D. B. Watson, I. P. Pavlov, B. F. Skinner, and E. T. Torndike;

- Dognitivism (W. Wundt, W. James, V. Keller, D. McClelland, J. Piaget, D. Rumelhart, EB Titchener, E. Tolman, G. Fechner, N. Chomsky, G. Ebbingaz, K. Rogers);

- The theory of stress (Stan B. Walters, IP Pavlov, W. Kennon, G. Selye);

- The theory of the unconscious (Z. Freud, C. G. Jung);

- The theory of accentuation of character and personality psychotypes (K. G. Jung, A. E. Lichko, K. Leonhard, E. Krechmer, E. Fromm, S. L. Rubinshtein, L. N. Sobchek, and A. Maslow);

- Psychoevolutionary theory of emotions (R. Pluchik, G. Kellerman, and H. R. Kont), as well as evolutionary theory of emotions (C. Darwin's statement that all emotions are universal regardless of sex, race, nationality, etc.), and other theories of emotions of scientists- psychologists/ 
b) Schools of Psychophysiology (V. M. Bekhterev, E. V. Vaske, L. S. Vygotsky, I. A. Ilin, A. P. Nechaev, I. P. Pavlov, V. V, Ponomarenko, V. S. Prerevozhensky, S. L, Rubinshtein, I. A. Tserkovnaya, Yu. K. Scherbatykh, and others);

c) Psychodiagnostics Schools (studying personality from the point of view of personal characteristics) in a broad sense, the ability to recognize (V. L. Tsvetkov)

d) Schools of Psycholinguistics (the study of speech from the moment of spontaneous and prepared statements, incongruity (contradiction) of verbal and nonverbal channels);

e) Schools of Social Psychology: E. Berne (social roles, games), V. Satir (communication models), etc.

f) Schools of Communication Psychology;

g) School of the Psychology of Lies/Truth (O. Fry, P. Eckman) [5, 6, 7, 8].

By taking knowledge of different branches of psychology, profiling allows us to solve the global problem, which is forecasting human behavior. Therefore, it is objectively in demand in any spheres of society's life. This complex interindustry approach stipulates its universal character as a professionally applied activity.

Legal psychology is able to borrow scientific permissible (legal) recommendations (psychotechnics, including profiling) in response to requests for legal activity as assistance in deep understanding, analysis of mental activity, states of the individual as an object of legal activity (behavior of subjects of criminal, civil, state legal relations) in various situations [9].

First, as a private complex, interdisciplinary psychological discipline, it includes and borrows the general knowledge from various branches of Psychological Sciences (underlying profiling) and the legal specifics of interaction, business communication in a specific field of activity (public authorities, state bodies, enterprises, institutions, organization, association of international, educational and scientific research level, different meetings and events, such as investigative, procedural actions, business meetings).

Second, the professional activity of a lawyer is also based on the objects of knowledge, which are characteristic of profiling.

In the system of legal knowledge, legal psychology, namely its psychotechnologies and psychotechnics, profiling in particular, is designed to solve the problems of other legal disciplines:

1) Substantive law (criminal, civil): consideration of subjective factors of criminal behavior, structure, motivational and emotional-volitional sphere, the level of intelligence, and mental states of a criminal (affects, stress, helpless state);

2) Procedural law (criminal, civil): the search and proving the truth, the facts to be established, i.e. proceeds in accordance with the psychological patterns of cognitive and emotional-volitional processes of the subject (lawyer);

3) Criminalistics: the development of investigative versions and tactics of the production of investigative actions (with the use of psychological knowledge and psychotechnics) and the choice of investigative methods. The appearance of a person is a subject of profiling;

4) Criminology: personality traits as a factor of crime (motivation, interests and needs, character, legal consciousness, psychophysiology, etc. for crime prevention); crime, personality, behavior of a criminal are the objects of studying in a number of sciences (interdisciplinary nature);

5) Forensic psychiatry, pathopsychology and clinical psychology, psychophysiology: the role of mechanisms of the pathology of the psyche in the development of unlawful behavior, psychophysiological reactions of the organism (a complex judicial psychopsychiatric-psycho-physiological examination).

\section{Conclusion}


Thus, profiling is an area of theoretical and methodological, interbranch and integrated, and therefore scientifically grounded knowledge in related disciplines of psychological science.

\section{References}

1. E. I. Voigel, A. A. Kozuleva, Siberian Criminal Procedural and Criminalistic Readings, 8, 2 (2017)

2. A. V. Kulik, N. A. Mostyuk, E. A. Guseva, Notes of the profiler: based on practical experience (Moscow, 2015)

3. E. N. Spiritsa, Psychology of lies and deception (Piter, Sant Petersburg, 2015)

4. S. B. Walters, The truth about the lie (Eksmo, Moscow, 2010)

5. P. Ekman, Psychology of lies: deceive me if you can (Piter, Saint Petersburg, 2018)

6. O. Fry, Lies: Three ways of revealing lies (Praim-Evroznak, Saint Petersburg, 2006)

7. About Your Self, Psychology for you: theory and practice (Moscow, 2017)

8. V. L. Tsvetkova, Profiling in the activities of the BIA (Yunity-Dana, Moscow, 2012)

9. M. Yu. Agrafonov, S. A. Karnovich, N. A. Sadohina, Legal psychology (VSI MVD, Irkutsk, 2014) 